Received:

$6-X-2020$

Accepted:

6-XII-2020

Published Online:

$11-\mid-2021$

\section{Evaluation of Fracture Strength and Total Void Amount in Composite Restorations on Endodontically Treated Teeth}

\section{Resistencia a la fractura y la cantidad total de burbujas en resinas}

\section{compuestas de dientes tratados endodónticamente}

Neslihan Tekçe DDS, PhD'; Seda Aydemir DDS, PhD2; Mustafa Demirci DDS, PhD;

Safa Tuncer D̉DS, PhD4; Selen Bozkaya DDS5; Elif Sevilay Yıldırım DDS6; Şeyma Akman DDS7

1. Department of Restorative Dentistry, Faculty of Dentistry, Kocaeli University, Kocaeli, Turkey. https://orcid.org/0000-0002-5447-3159

2. Department of Endodontics, Faculty of Dentistry, Kocaeli University, Kocaeli, Turkey.

https://orcid.org/0000-0003-2299-2138

3. Department of Restorative Dentistry, Faculty of Dentistry, Istanbul University, Istanbul, Turkey. https://orcid.org/0000-0001-5585-1935

4. Department of Restorative Dentistry, Faculty of Dentistry, Istanbul University, Istanbul, Turkey. https://orcid.org/0000-0003-2101-3225

5. Department of Restorative Dentistry, Faculty of Dentistry, Kocaeli University, Kocaeli, Turkey. https://orcid.org/0000-0001-8742-4508

6. Department of Restorative Dentistry, Faculty of Dentistry, Kocaeli University, Kocaeli, Turkey. https://orcid.org/0000-0001-8919-3504

7. Department of Restorative Dentistry, Faculty of Dentistry, Kocaeli University, Kocaeli, Turkey.

https://orcid.org/0000-0001-8166-798X

Correspondence to: Dr. Neslihan Tekçe - neslihan_arslann@hotmail.com

ABSTRACT: The aim of the study was to investigate the fracture strength of different composite resins and the quantity of voids in conventional posterior composite, highflow flowable composite, bulk-fill flowable composite, and fiber-reinforced composite. Forty-four caries-free, freshly extracted mandibular premolars were used for this study. Teeth were prepared for cavity and root canal treatment. Subsequently, root canal treatment was applied to the teeth and cavities in order to prepare them for restorations. The specimens were then divided into four groups: group-1: Estelite Posterior; group-2: Estelite Flow Quick High Flow; group-3: Estelite Bulk-fill Flow; group-4: everX Posterior. One specimen from each experimental group was examined using micro-CT to perform measurement of voids. The fracture strength values of high-flow flowable, bulk-fill flowable, fiber-reinforced, and conventional microhybrid composites were found to be similar $(p=0.497)$. EverX Posterior showed the highest fracture strength values $(841.1 \pm 149.4 \mathrm{~N})$, followed by Estelite Bulk-fill Flow $(822.8 \pm 170.8 \mathrm{~N})$. Volume of voids (\%) obtained from Micro-CT analysis revealed that restorations with high-flow liner or bulk-fill flowable exhibited more voids. The fiber-

TEKÇE N., AYDEMIR S., DEMIRCI M., TUNCER S., BOZKAYA S., YILDIRIM E.S., AKMAN S.., 2021: Evaluation of Fracture Strength and Total Void Amount in Composite Restorations on Endodontically Treated Teeth-ODOVTOS-Int. J. Dental Sc. 23-3 (September-December): 75-86. 
reinforced composite showed the lowest percentage volume of incorporating voids and the highest fracture strength results.

KEYWORDS: Bulk-fill composite; Flowable composite; Fiber-reinforced composite; Fracture strength; Micro-computed tomography; Posterior composite.

RESUMEN: El objetivo del estudio fue investigar la resistencia a la fractura de diferentes resinas compuestas y la cantidad de burbujas en resinas posteriores convencionales, resinas fluidas de alto flujo, resinas fluidas tipo bulk-fill y resinas reforzados con fibras. Cuarenta y cuatro premolares mandibulares libres de caries, recién extraídos, fueron usados para este estudio. Los dientes se prepararon para el tratamiento de conductos radiculares y las cavidades para prepararlos para las restauraciones. Los especímenes se dividieron en cuatro grupos: Grupo-1: Estelite Posterior; Grupo-2: Estelite Flow Quick High Flow; Grupo-3: Estelite Bulk-fill Flow; Grupo-4: everX Posterior. Un espécimen de cada grupo experimental fue examinado usando micro-CT para realizar la medición de las burbujas. Los valores de resistencia a la fractura de los compuestos de alto flujo, flujo de relleno, reforzados con fibra y microhíbridos convencionales fueron similares $(p=0,497)$. EverX Posterior mostró los valores más altos de resistencia a la fractura $(841,1 \pm 149,4 \mathrm{~N})$, seguido de Estelite Bulk-fill Flow $(822,8 \pm 170,8$ N). El volumen de las burbujas (\%) obtenido del análisis de Micro-TC reveló que las restauraciones con revestimiento de alto flujo o con flujo de relleno a granel presentaban más huecos. El compuesto reforzado con fibra mostró el menor porcentaje de volumen de incorporación de vacíos y los resultados más altos de resistencia a la fractura.

PALABRAS CLAVE: Resina Bulk-fill; Resina fluida; Resina reforzada con fibra; Resistencia a la fractura; Tomografía microcomputarizada; Resina posterior.

\section{INTRODUCTION}

As a result of the increase in esthetic demand and the development of adhesive techniques, composite restorative materials are more preferred for the restoration of anterior and posterior teeth by the practitioners (1). The application procedures of dental adhesives and composite can influence the clinical performance of restorations. The correct use of dental adhesives and materials achieves successful bonding and complete adaptation that is free of porosities and voids (2). Large voids may lead to a lower resistance to fracture and may be responsible for marginal discoloration or microleakage (2). Voids in materials and non-polished surfaces would multiply stress severity and thus initiate fracture (3).

Using micro-computed tomography (micro-CT) provides a detailed 3D reconstruction of dental restorations and surrounding structures, which can be sliced in any direction to obtain accurate information of their internal geometric properties and structural parameters $(4,5)$. One of the advantages of micro-CT is its ability to be non-destructive, especially with temporal evaluation (4). Micro-CT has been used for various approaches in dental materials research (6), including quantification of interfacial void fraction in composite restorations (7), determining the presence and quantification of 
micro-leakage $(4,6)$, and the direction and amount of polymerization shrinkage $(5,8)$, as well as for measuring internal adaptation (9).

In recent years, many innovations have been made in the content of materials to facilitate their clinical use and to improve their mechanical properties. Estelite Posterior is a light-cured, radiopaque composite resin for use in posterior restorations. This material contains silica-zirconia filler (84-70 wt-vol\%) that offers a decreased polymerization shrinkage ratio. Bulk-fill composites provide ease of use for composites, and fibercontaining composites strengthen composites and increase the durability of the materials. EverX Posterior is a fiber-containing composite that was developed in recent years. EverX Posterior is a fiber-reinforced composite for use as a dentin replacement. Especially in large cavities, short fibers prevent crack propagation. Estelite Bulk-fill Flow is a resin-based flowable-bulk-filled restorative that contains supra-nano spherical filler (70-56 wt-vol\%). Estelite Bulk-fill Flow is an up-to-date material that provides easy use for clinicians, allowing for thick-layered composites to be used. Estelite Flow Quick High Flow contains silica-zirconia filler (68-49 wt-vol\%). It provides high polymerization activity and fast curing.

In order to achieve a good cavity adaptation of restorative materials; it is imperative to consider the handling features and adaptation modes of composites (10). The possibility of creating voids between increments, the difficulty in placement for composite layers, and the increased time required for layering are some of the disadvantages of the incremental technique (11-13). Void creation, in particular, which is related to the increased time required to place and polymerize each layer separately, may affect fracture strength of endodontically-treated teeth that have already been disturbed. Hence, this study examined the effect of different composite material choices (conventional posterior composite, high-flow flowable composite, bulk-fill flowable composite, and fiber-reinforced composite) on fracture strength and quantity of incorporating voids in the material. The tested hypothesis was "different composite material choices for incremental technique affect the fracture strength of endodontically-treated teeth."

\section{MATERIALS AND METHODS}

The study protocol was approved by the Ethics Committee of Kocaeli University (KU GOKAEK 2016/268). The materials used are presented in detail in Table 1. Forty-four cariesfree, freshly extracted human mandibular premolars with near-identical dimensions (8-mm buccallingual and 7-mm mesiodistal widths) were used for this study. Digital calipers (Mitutoyo, Corp, Kawasaki, Japan) were used for each measurement. Chloramine $\mathrm{T}(0.5 \%)$ solution was used to disinfect the teeth, which were then used within one month. The roots of the teeth were covered with a polyether impression material and embedded in an auto-polymerizing acrylic resin up to $2 \mathrm{~mm}$ below the cementoenamel junction.

All specimens received root canal treatment. First, endodontic access cavities were prepared, and pulp tissue was removed using barbed broaches. A size 15K file (Mani Inc., Toshigi-Ken, Japan) was placed passively until it reached the apical foramen. The working length was established as $0.5 \mathrm{~mm}$ shorter than the measured length. Protaper nickel-titanium rotary instruments were used to prepare the root canals till achieving size F2 (Dentsply Maillefer, Baillagues, Switzerland). The root canals were irrigated with $2 \mathrm{~mL}$ of $2.5 \%$ sodium hypochlorite before each change of instruments. The canals were dried using paper points. A lateral compaction technique using gutta-percha (Diadent, Choong Chong Buk Do, Korea) and an Ah Plus (Dentsply-DeTrey, Konstanz, Germany) root canal sealer was used to obdurate the root canals. The teeth were kept in $100 \%$ humidity at $37^{\circ} \mathrm{C}$ for 7-days to ensure settlement of the materials. 
Following root canal treatment, standard cavities were prepared using a high-speed hand-piece for all endodontically-treated teeth. Six-degree tapered diamond burs were used to prepare the cavities. The pulpal floor and occlusal isthmus were prepared to a depth and width of 4-mm and 2-mm, respectively (14). All measurements were controlled with a caliper and periodontal probe to ensure that all preparations were of a standardized size. Margins were not beveled. After cavity preparation, the teeth were divided into groups. All materials were used in accordance with the manufacturer's recommendations. All composites were placed into cavities using a Tofflemire matrix system. The groups $(n=10)$ were designed in the following way:

Group 1:Self-etching bonding agentTokuyama Bond Force II (Tokuyama Dental Corporation, Tokyo, Japan) was applied to cavity walls, and an Elipar S10 LED unit (3M ESPE, St Paul, USA) was used to achieve polymerization $\left(1200 \mathrm{~mW} / \mathrm{cm}^{2}\right)$ for $10 \mathrm{~s}$. The micro-hybrid composite, Estelite Posterior (Tokuyama Dental Corporation), was placed into the cavities in two 2-mm increments; each was polymerized for 10 s.

Group 2: Tokuyama Bond Force II was applied to cavity walls and polymerized. Estelite Flow Quick High Flow (Tokuyama Dental Corporation) was located into the cavities in one 2-mm increment and light-cured for 10s. Estelite Posterior was then applied to the cavities in one 2-mm increment and light-cured for 10 s.

Group 3: Tokuyama Bond Force II was applied to the cavity walls and polymerized. Estelite Bulk-fill Flow (Tokuyama Dental Corporation) was located into the cavities in one 2-mm increment and light-cured for 10s. Estelite Posterior was then placed into the cavities in a 2-mm increment and light-cured for 10 s.

Group 4: G Premio Bond (GC Corporation, Tokyo, Japan) was applied to the cavity walls and cured for 10s. A maximum 3mm of everX Posterior (GC Corporation) was placed into the cavities and polymerized for 40s, and then the remaining occlusal part was restored using a single layer of $G$ Aenial Posterior (GC Corporation), which was polymerized for 20 s.

After polymerization, a Sof-Lex disc (3M ESPE) was used for finishing and polishing at each restoration margin. Each restoration was stored in water at $37^{\circ} \mathrm{C}$ for $24 \mathrm{~h}$. A universal testing machine (Instron 6022, Instron Corp., MA, USA) was used at a crosshead speed of $0.5 \mathrm{~mm} / \mathrm{min}$ to evaluate the fracture strength. Using a $3 \mathrm{~mm}$-diameter stainless steel rod, teeth from each group underwent the fracture strength test. The rod was centered on the occlusal surface of the restoration, and force was applied vertically until failure (14-16). The fracture strength value and fracture mode of each specimen were recorded and showed in Table 2 $(17-19)$

One specimen from each group was selected for void measurements. Skyscan 1172 (Bruker Company) resolution micro-computed tomography $(\mu \mathrm{CT})$ equipment was used for the measurements at Sabancı University, Nanotechnology Research and Application Center. The long axis of each specimen was positioned perpendicular to the floor of the micro-CT specimen holder, and the specimens were scanned at 360-degree rotations. The teeth were reconstructed using NRecon (version 1.6.9.4) software, which uses a modified Feldkamp's back-projection. The 3D reconstructions, containing grayscale values for each voxel (3D pixel), were 
segmented (binarized) using the peak-valley method and analyzed on a CT-An (CT-Analyser, version 1.14.4.1) (20).

Statistical analysis was performed using IBM SPSS for Windows version 20.0 (SPSS, Chicago, IL, USA). The Kolmogorov-Smirnov test was used to test the normality of data distribution. Continuous variables were compared between the groups using one-way ANOVA and the Tukey post-hoc test $(p<0.05)$.

\section{RESULTS}

Table 2 shows the mean and standard deviation values. No statistically significant difference was found between the fracture strength values of the four groups $(p=0.497)$. EverX Posterior showed the highest fracture strength values $(841.1 \pm 149.4 \mathrm{~N})$,

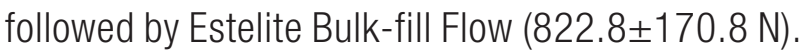

Figures 1-4 show the percentages of the volumes of voids and cross-sectional images obtained from the micro-CT analysis of each group. The lowest percentage volume of voids was observed in group 4 . The teeth from group 2 showed the highest percentage volume of voids, followed by groups 3 and group 1, respectively. Fracture pattern characteristics are presented in Table 2. When the fracture modes were analyzed of specimens in all groups, it was observed that the mode I and II fractures were more frequent.

Table 1. Materials used in the study.

\begin{tabular}{|c|c|c|c|c|}
\hline Material & Type & Organic content & Inorganic content & $\begin{array}{c}\text { Filler quantity } \\
\text { (wt/vol \%) }\end{array}$ \\
\hline $\begin{array}{l}\text { Tokuyama Bond Force II } \\
\text { (Tokuyama Dental, Tokyo, } \\
\text { Japan) }\end{array}$ & Self-etching bonding agent & $\begin{array}{l}\text { Phosphoric acid monomer, } \\
\text { Bis-GMA, TEGDMA, HEMA, } \\
\text { alcohol, water }\end{array}$ & - & - \\
\hline $\begin{array}{l}\text { G Premio Bond } \\
\text { (GC Corp., Tokyo, Japan) }\end{array}$ & $\begin{array}{l}\text { One-component light- } \\
\text { cured universal adhesive }\end{array}$ & $\begin{array}{l}\text { MDP, 4-MET, MDTP, BHT, } \\
\text { DMA, acetone, water }\end{array}$ & Silica & NA \\
\hline $\begin{array}{l}\text { Estelite Posterior } \\
\text { (Tokuyama Dental, Tokyo, } \\
\text { Japan) }\end{array}$ & Micro-hybrid composite & $\begin{array}{l}\text { Bis-GMA, TEGDMA, } \\
\text { Bis-MPEPP }\end{array}$ & Silica-zirconia filler & $84 / 70$ \\
\hline $\begin{array}{l}\text { Estelite Flow Quick High } \\
\text { Flow } \\
\text { (Tokuyama Dental, Tokyo, } \\
\text { Japan) }\end{array}$ & Flowable composite & Bis-GMA and TEGDMA & Silica-zirconia filler & $68 / 49$ \\
\hline $\begin{array}{l}\text { Estelite Bulk Fill Flow } \\
\text { (Tokuyama Dental, Tokyo, } \\
\text { Japan) }\end{array}$ & bulk-fill composite & $\begin{array}{l}\text { Bis-GMA, TEGDMA, } \\
\text { Bis-MPEPP, Mequinol, } \\
\text { Dibutyl hydroxyl toluene } \\
\text { and UV absorber }\end{array}$ & $\begin{array}{l}\text { Spherical silica-zirconia } \\
\text { filler }\end{array}$ & $70 / 56$ \\
\hline $\begin{array}{l}\text { everX Posterior } \\
\text { (GC Corp., Tokyo, Japan) }\end{array}$ & $\begin{array}{l}\text { Short fiber-reinforced } \\
\text { composite }\end{array}$ & Bis-GMA, TEGDMA, PMMA & $\begin{array}{l}\text { E-glass fibers, barium } \\
\text { glass }\end{array}$ & $74.2 / 53.6$ \\
\hline $\begin{array}{l}\text { G Aenial Posterior } \\
\text { (GC Corp., Tokyo, Japan) }\end{array}$ & $\begin{array}{l}\text { Micro-hybrid } \\
\text { composite }\end{array}$ & $\begin{array}{l}\text { UDMA, Dimethacrylate } \\
\text { co-monomer } \\
\text { (Bis-GMA free) }\end{array}$ & $\begin{array}{l}\text { Fluoro alumino } \\
\text { silicate, fumed silica, } \\
\text { pre-polymerized fillers, } \\
\text { silica, strontium and } \\
\text { lanthanoid fluoride }\end{array}$ & $77 / 65$ \\
\hline
\end{tabular}

Bis-GMA: Bisphenol A glycidyl methacrylate; MDP: 10-methacryloyloxydecyl dihydrogen phosphate; 4-MET: 4-methacryloyloxyethyl trimellitate; MDTP: 10-methacryoyloxydecyl dihydrogen thiophosphate; BHT: butylated hydroxytoluene; TEGDMA: Triethylene glycol dimethacrylate; Bis-MPEPP: Bisphenol A polyethoxy methacrylate; PMMA: polymethyl methacrylate.

NA: Not available. 
Table 2. Mean fracture resistance values (Newton), standard deviations and fracture type of all experimental groups.

\begin{tabular}{ccccccc}
\hline Groups & $\begin{array}{c}\text { Fracture } \\
\text { Strength (N) }\end{array}$ & $\begin{array}{c}\text { Standard } \\
\text { Deviation ( }\end{array}$ & \multicolumn{5}{c}{ Fracture Mode } \\
\cline { 4 - 7 } & 739.3 & 195.6 & Mode I & Mode II & Mode III & Mode IV \\
\hline Group 1 & 741,8 & 148 & 2 & 5 & 3 & - \\
Group 2 & 822.8 & 170.8 & 3 & 7 & 1 & - \\
Group 3 & 841.1 & 149.4 & 4 & 4 & - & - \\
Group 4 & & &
\end{tabular}

Mode I: Fracture of a small portion of coronal tooth structure. Mode II: Fracture of a small portion of coronal tooth and restoration. Mode III: Fracture of tooth structure, restoration cohesion and/or adhesive failure, with root involvement that is restorable with periodontal surgery. Mode IV: Severe root and crown fracture requiring tooth extraction.
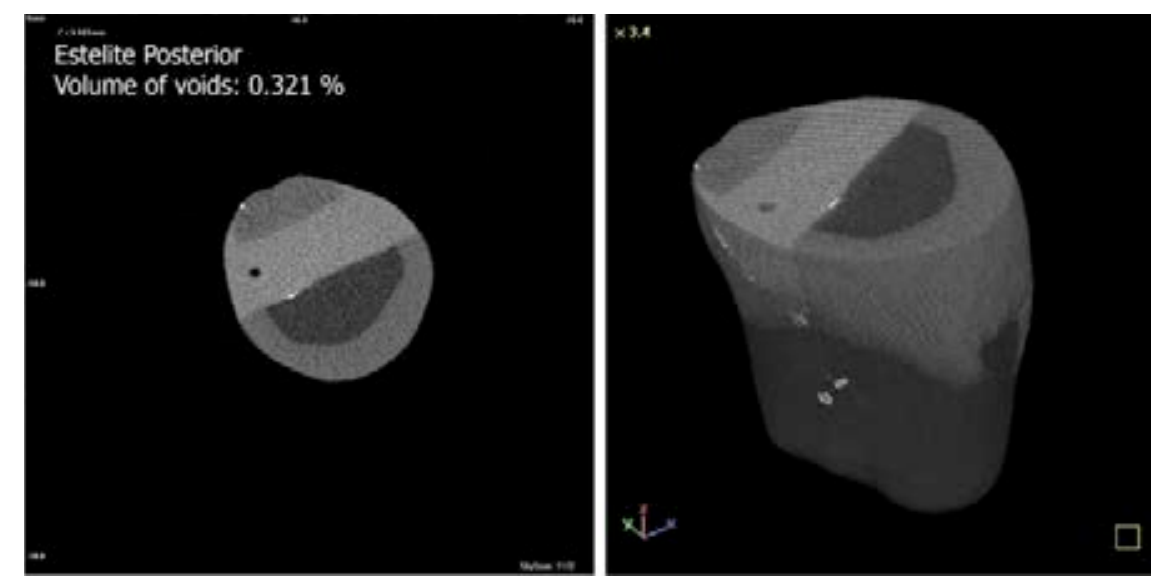

Figure 1. Voids in composite restoration prepared with Estelite Posterior with an incremental technique.

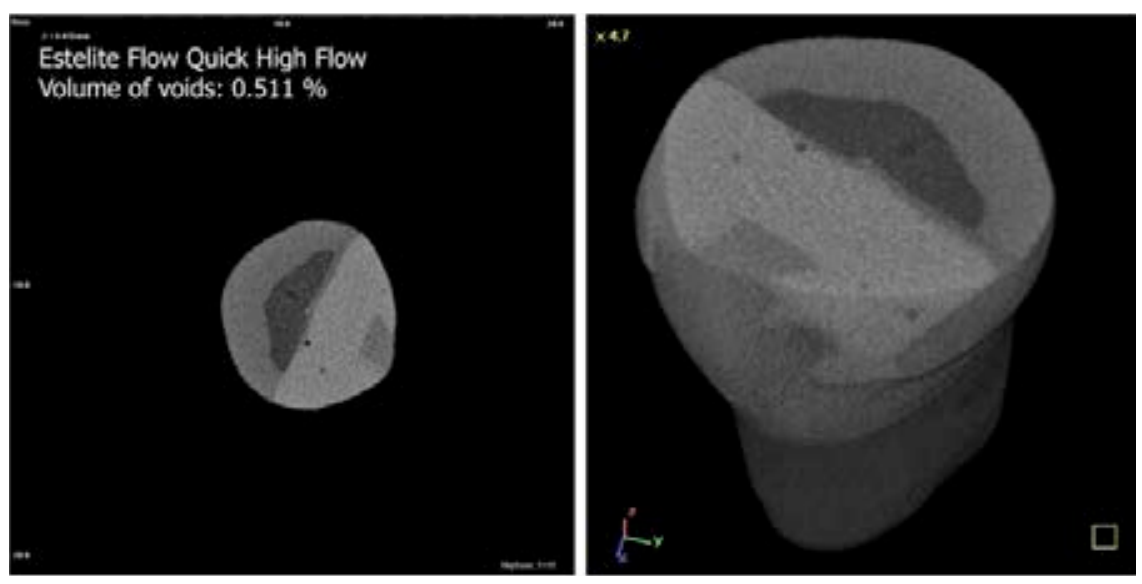

Figure 2. Voids in composite restoration prepared with Estelite Flow Quick High-Flow and Estelite Posterior. 


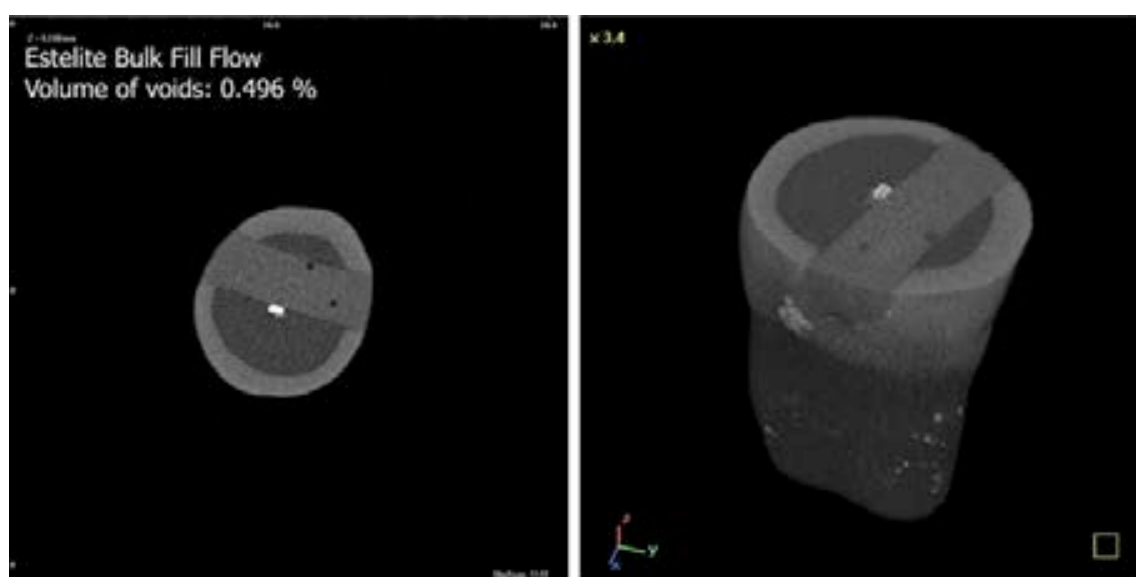

Figure 3. Voids in composite restoration prepared with Estelite Bulk-fill Flow and Estelite Posterior.

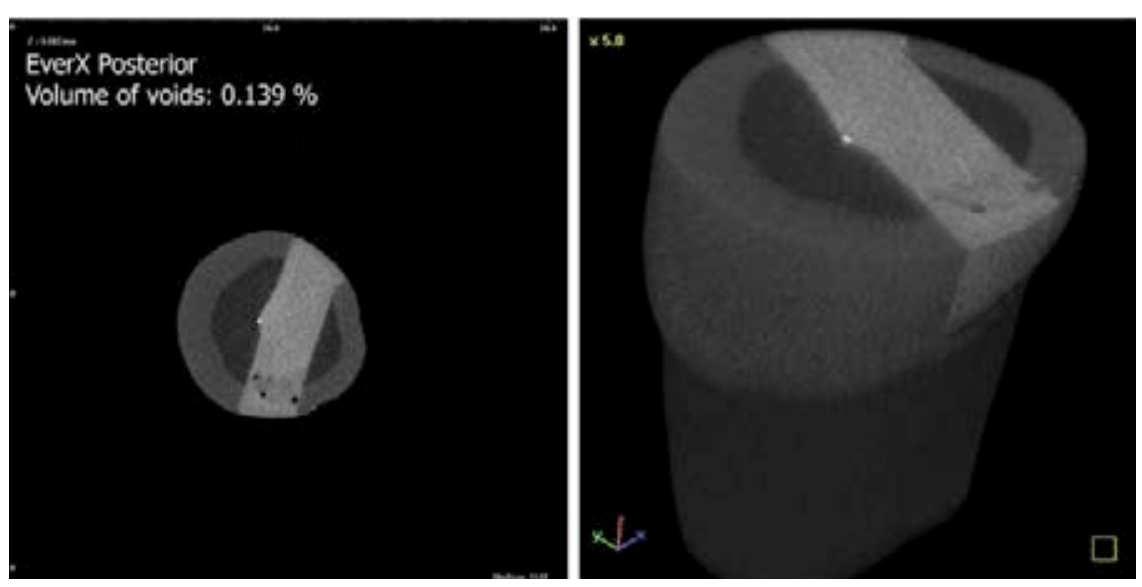

Figure 4. Voids in composite restoration prepared with everX Posterior and G Aenial Posterior.

\section{DISCUSSION}

The study was conducted to investigate the fracture strength of different composite resins and the quantity of voids in materials. The results revealed that material choices for the incremental technique had no effect on fracture strength of endodontically-treated teeth. Thus, our hypothesis of "different composite material choices for incremental technique affect the fracture strength of endodontically-treated teeth" must be rejected. There were no significant differences between the fracture strengths of conventional posterior composite, high-flow flowable composite, bulk-fill flowable composite, and fiber-reinforced composite. Also, the micro-CT analysis revealed that the materials had fewer voids, ranging between (0.139 to 0.511 volume\%).

Several studies reported that there were no statistically significant differences between the fracture strengths of sound teeth and experimental groups; thus, restorative procedures significantly strengthen weakened tooth structures $(16,21-23)$. It was reported that cavity preparation weakened teeth, and that teeth were at higher risk for fracture 
after tooth structure continuity was broken $(24,25)$. The different aspects of preparation have individual or group contributions to the weakening effect of prepared teeth (26). Moreover, endodonticaccess cavity preparations weaken teeth because they produce a deep and extended cavity, which reduces the amount of dentin $(24,25)$. The use of more conservative cavity preparation techniques and direct resin composite restorations provides a strengthening effect and significantly increases fracture resistance (22). This may explain the lack of a significant difference between the groups in our study.

In our previous in vitro study (16), we investigated the effect of different fabrication techniques on fracture strengths of composite resin-based inlay restorations of endodontically treated molars. We found that each restorative material (indirect composite or CAD/CAM resin) exhibited statistically similar fracture strength results to each other, and they could be applied safely to endodontically-treated molars to achieve sufficient fracture resistance. Similarly, the present work also showed that there was no significant difference between the fracture strengths of flowable, bulk-fill flowable, fiber-reinforced composite, and conventional micro-hybrid composite on endodontically-treated premolars. Atalay et al. reported that the fracture strengths of endodonticallytreated teeth restored using either bulk-fill/bulk-fill flowable or fiber-reinforced composite were not different from those restored with conventional nanohybrid resin composite (27). Interestingly, everX Posterior exhibited lower fracture strength than in our study (27). This may have been caused by differences in teeth types or dimensions of MOD cavity between the studies. Similar to our findings, it was shown that everX Posterior, flowable, and conventional paste composite exhibited similar fracture strength results in endodontically-treated molar MOD cavities (14).
Kemaoloğlu et al. found 889.43N fracture strength values in endodontically-treated mandibular premolars for EverX Posterior. The authors concluded that fiber reinforcement enhanced the fracture strength of teeth with large MOD cavities compared with bulk-fill and nano-hybrid resin composites (28). Another study found that everX Posterior under large composite restorations resulted in fracture resistance resembling that of intact teeth (21). Garoushi et al. reported that everX Posterior, which contains a resin matrix, inorganic particulate fillers, and randomly orientated electrical-glass fibers, had more developed physical properties compared with conventional composites and recommended its use in high stress-bearing areas (29). It was explained that the reinforcing effect of the fiber fillers was based on the stress transfer from the polymer matrix to the fibers, and also that each individual fiber acted as a crack stopper (29). It has also been shown that short fibers could stop crack propagation and provides enhanced fracture resistance of composite resins (30).

In the present study, bulk-fill flowable composite showed similar fracture strength values with high-flow composite and conventional microhybrid composite. These findings are in agreement with the study of $\mathrm{Toz}$ et al., who reported no difference between the fracture strengths of bulk-fill flowable composite and conventional resin composite restorations in endodontically-treated teeth (31). Furthermore, another study evaluated the fracture resistance of endodontically-treated teeth restored using nano-hybrid composite resin, bulk-fill flowable, and short fiber-reinforced composite in the absence/presence of retention slots. The researchers reported that there were no differences between the restorative materials (32). Flowable composites have a filler size that resembles hybrid composites, but lower filler content than their hybrid analogs. The present study included two flowable composites, which 
have higher filler content between $49 \%$ and $56 \%$ by volume. Filler volume appeared to have the most elevated impact on the measured properties, inducing a maximum flexural strength and flexural modulus at a level of $60 \%$ (33). In the present study, bulk-fill flow and high-flow composite resin were used as liners under microhybrid composites. The fracture strengths of these groups were similar to group 1, which included only micro-hybrid composite restorations (filler content: $70 \%$ vol) without a liner. Thus, enhanced filler levels do not seem to be the only factor that affects fracture strength results. Organic contents, filler types, or void amounts may affect the results. On the other hand, flowable resin composites may act as an intermediate and stress-breaker layer (27). Therefore, bulk-fill flow and high-flow composite resins may show similar fracture strengths to conventional composites. Bayne et al. (34) reported that flowable composites with the least flow were similar to traditional composites, concluding that flowable restorative dentistry materials in high-stress applications should be used with caution (34).

In accordance with the findings of a previous study, we analyzed the failure modes in each test group on molar teeth, and the results indicated that short fiber everX Posterior-restored specimens were prone to irreparable fractures with periodontal involvement, which may be related to the improved mechanical properties of fiber materials (14). However, in the current study, most failure modes were mode 1 or 2 . This may be related to different types of teeth (molar or premolar) and the lack of strength of premolars compared with molars. Molar teeth are much larger in volume than premolar teeth. The differences between fracture types may also have arisen from micro-fractures on thin cusps for premolar teeth, thus causing increasing reparable types of fractures.

According to the micro-CT analysis, all materials had a small number of voids; conventional posterior composite (0.321 vol\%), high-flow flowable composite (0.511 vol\%), bulk-fill flowable composite (0.496 vol\%), and fiberreinforced composite (0.139 vol\%). Restorations with a high-flow flowable or bulk-fill flowable liner exhibited more incorporating voids than fiber-reinforced and conventional micro-hybrid composites. In contrast to our findings, Optam et al. showed that the use of packable high-viscosity materials clearly increased the risk of voids and porosities in restorations (35). This difference may be due to the use of different test methodologies because they used light microscopy to evaluate porosities. In support of our findings from the micro-CT analysis, it was reported that the void presence may be the result of undue handling of flowable composites. Any stirring motion or violent injection causes void formation (36). It was shown that the tendency to void formation was significantly different among various flowable composites, and it was material dependent (37).

As in many in vitro studies, this study has some limitations. Performing the study under laboratory conditions and the lack of thermal stress on specimens are only a few of them. It must be kept in mind that the teeth and the restorative materials are constantly exposed to several forces, and they are affected by different factors. Thus, the clinical conditions must be attentively taken into account.

\section{CONCLUSION}

When all limitations of this study are considered, all resin composite materials used to restore endodontically treated teeth produced similar fracture strength values. However, the combination of everX Posterior and G Aenial Posterior exhibited higher fracture strengths than the other test groups. Also, micro-CT measurements revealed that the lowest amount of volume of voids (\%) was obtained from fiber-reinforced composite, followed by conventional micro-hybrid composite. 
ACKNOWLEDGMENTS

The study was supported by the Kocaeli University, Scientific Research Project Unit (research project number 230).

\section{REFERENCES}

1. Park J., Chang J., Ferracane J., Lee I.B. How should composite be layered to reduce shrinkage stress: incremental or bulk-filling? Dent Mater. 2008; 24 (11): 1501-5.

2. Opdam N.J., Roeters J.J., Peters T.C., Burgersdijk R.C., Teunis M. Cavity wall adaptation and voids in adhesive Class I resin composite restorations. Dent Mater. 1996; 12 (4): 230-5.

3. Baudin C., Osorio R., Toledano M., de Aza S. Work of fracture of a composite resin: fracture-toughening mechanisms. J Biomed Mater Res A. 2009; 89 (3): 751-8.

4. Carrera C.A., Lan C., Escobar-Sanabria D., Li Y., Rudney J., Aparicio C., Fok A. The use of micro-CT with image segmentation to quantify leakage in dental restorations. Dent Mater. 2015; 31 (4): 382-90.

5. Li H., Li J., Yun X., Liu X., Fok A.S. Non-destructive examination of interfacial debonding using acoustic emission. Dent Mater. 2011; 27 (10): 964-71.

6. Neves A.A., Jaecques S., Van Ende A., Cardoso M.V., Coutinho E., Lührs A.K., Zicari F., Van Meerbeek B. 3D-microleakage assessment of adhesive interfaces: exploratory findings by $\mu C T$. Dent Mater. 2014; 30 (8): 799-807.

7. Kakaboura A., Rahiotis C., Watts D., Silikas N., Eliades G. 3D-marginal adaptation versus setting shrinkage in light-cured microhybrid resin composites. Dent Mater. 2007; 23 (3): 272-8

8. Chiang Y.C., Rösch P., DabanogluA., Lin C.P., Hickel R., Kunzelmann K.H. Polymerization composite shrinkage evaluation with $3 \mathrm{D}$ deformation analysis from microCT images. Dent Mater. 2010; 26 (3): 223-31.

9. Han S.H., Park S.H. Comparison of internal adaptation in Class II bulk-fill composite restorations using micro-CT. Oper Dent. 2017; 42 (2): 203-14.

10. Chuang S.F., Liu J.K., Chao C.C., Liao F.P., Chen Y.H. Effects of flowable composite lining and operator experience on microleakage and internal voids in class II composite restorations. J Prosthet Dent. 2001; 85 (2): 177-83.

11. Lazarchik D.A., Hammond B.D., Sikes C.L., Looney S.W., Rueggeberg F.A. Hardness comparison of bulk-filled/transtooth and incremental-filled/occlusally irradiated composite resins. J Prosthet Dent. 2007; 98 (2): $129-40$.

12. Abbas G., Fleming G.J., Harrington E., Shortall A.C., Burke F.J. Cuspal movement and microleakage in premolar teeth restored with a packable composite cured in bulk or in increments. J Dent. 2003; 31 (6): 437-44.

13. Neiva I.F., de Andrada M.A., Baratieri L.N., Monteiro Júnior S., Ritter A.V. An in vitro study of the effect of restorative technique on marginal leakage in posterior composites. Oper Dent. 1998; 23 (6): 282-9.

14. Tekçe N., Pala K., Tuncer S., Demirci M., Serim M.E. Influence of polymerisation method and type of fibre on fracture strength of endodontically treated teeth. Aust Endod J. 2017; 43 (3):115-22

15. Tekçe N., Pala K., Demirci M., Tuncer S., Özel E., Göktürk S.A., Karakuyu H. Fracture strength of composite resins for endodontically treated molars. J Adhes Sci Technol. 2016; 30 (24); 2745-56.

16. Tekçe N., Pala K., Demirci M., Tuncer S. Influence of different composite materials and cavity preparation designs on the fracture resistance of mesio-occluso-distal inlay restoration. Dent Mater J. 2016; 35 (3): 523-31. 
17. Burke F.J., Wilson N.H., Watts D.C. The effect of cavity wall taper on fracture resistance of teeth restored with resin composite inlays. Oper Dent. 1993; 18 (6): 230-6.

18. Soares P.V., Santos-Filho P.C., Martins L.R., Soares C.J. Influence of restorative technique on the biomechanical behavior of endodontically treated maxillary premolars. Part I: fracture resistance and fracture mode. J Prosthet Dent. 2008; 99 (1): 30-7.

19. Saridag S., Sari T., Ozyesil A.G., Ari Aydinbelge $H$. Fracture resistance of endodontically treated teeth restored with ceramic inlays and different base materials. Dent Mater J. 2015; 34 (2): 175-80.

20. Sarıdağ S., Helvacioğlu-Yiğit D., Özcan M., Avcu E., Kızıltaş G. Micro-computerized tomography analysis of cement voids and pull-out strength of glass fiber posts luted with self-adhesive and glass-ionomer cements in the root canal. J Adhes Sci Technol. 2016; 30 (14): 1585-95.

21. Ozsevik A.S., Yildirim C., Aydin U., Culha E., Surmelioglu D. Effect of fibre-reinforced composite on the fracture resistance of endodontically treated teeth. Aust Endod J. 2016; 42 (2): 82-7.

22. Taha N.A., Palamara J.E., Messer H.H. Fracture strength and fracture patterns of root filled teeth restored with direct resin restorations. J Dent. 2011; 39 (8): 527-35.

23. Steele A., Johnson B.R. In vitro fracture strength of endodontically treated premolars. J Endod. 1999; 25 (1): 6-8.

24. Reeh E.S., Messer H.H., Douglas W.H. Reduction in tooth stiffness as a result of endodontic and restorative procedures. J Endod. 1989; 15 (11): 512-6.

25. Owen C.P. Factors influencing the retention and resistance of preparations for cast intracoronal restorations. J Prosthet Dent. 1986; 55 (6): 674-7.
26. St-Georges A.J., Sturdevant J.R., Swift E.J. Jr., Thompson J.Y. Fracture resistance of prepared teeth restored with bonded inlay restorations. J Prosthet Dent. 2003; 89 (6): $551-7$.

27. Atalay C., Yazici A.R., Horuztepe A., Nagas E., Ertan A., Ozgunaltay G. Fracture resistance of endodontically treated teeth restored with bulk-fill, bulk-fill flowable, fiber-reinforced, and conventional resin composite. Oper Dent. 2016; 41 (5): 131-40.

28. Kemaloglu H., Emin Kaval M., Turkun M., Micoogullari Kurt S. Effect of novel restoration techniques on the fracture resistance of teeth treated endodontically: An in vitro study. Dent Mater J. 2015; 34 (5): 618-22.

29. Garoushi S., Säilynoja E., Vallittu P.K., Lassila L. Physical properties and depth of cure of a new short fiber reinforced composite. Dent Mater. 2013; 29 (8): 835-41.

30. Garoushi S., Vallittu P.K., Lassila L.V. Short glass fiber reinforced restorative composite resin with semi-inter penetrating polymer network matrix. Dent Mater. 2007; 23 (11): 1356-62.

31. Toz T., Tuncer S., Bozkurt F.O., Tuncer A.K., Bag H.G. The effect of bulk-fill flowable composites on the fracture resistance and cuspal deflection of endodontically treated premolars. J Adhes Sci Technol. 2015; 29 (15): 1581-92.

32. Yasa B., Arslan H., Yasa E., Akcay M., Hatirli H. Effect of novel restorative materials and retention slots on fracture resistance of endodontically-treated teeth. Acta Odontol Scand. 2016; 74 (2): 96-102.

33. Ilie N., Hickel R. Investigations on mechanical behaviour of dental composites. Clin Oral Invest. 2009; 13 (4): 427-38.

34. Bayne S.C., Thompson J.Y., Swift E.J. Jr., Stamatiades P., Wilkerson M. A 
characterization of first-generation flowable composites. J Am Dent Assoc. 1998; 129 (5): 567-77.

35. Opdam N.J., Roeters JJ, Joosten M, Veeke Ov. Porosities and voids in Class I restorations placed by six operators using a packable or syringable composite. Dent Mater. 2002; 18(1): 58-63.

36. Chuang S.F., Liu J.K., Chao C.C., Liao F.P., Chen Y.H. Effects of flowable composite lining and operator experience on microleakage and internal voids in class II composite restorations. J Prosthet Dent. 2001; 85 (2): 177-83.

37. Nazari A., Sadr A., Saghiri M.A., CampilloFunollet M., Hamba H., Shimada Y., Tagami J., Sumi Y. Non-destructive characterization of voids in six flowable composites using swept-source optical coherence tomography. Dent Mater. 2013; 29 (3): 278-86. 